\title{
LIRG News
}

\section{Chairman's Report for 1994/5}

\section{Committee}

The usual four committee meetings have been held during the year (June, October, December and March). I should like to record my thanks to Committee members who work so hard on behalf of the Group. Special thanks go to Monica Blake who is leaving the Committee this year after many years. Monica has been Reviews Editor for LIRN and has been involved in running many meetings, particularly the LIRG-SE evening meeting.

\section{Meetings}

A very successful one day course $\underline{A}$ question of research was held in York on 14 July. This introduction to research presented through case studies was fully subscribed with a cross-section of participants. It is hoped to repeat this seminar in another part of the country at some future date. Thanks are due to the organizing group of Committee members. Various suggestions for further seminars and meetings have come to the Committee. There is certainly no shortage of ideas. The only problem seems to be finding the time to develop them.

The conference, Better by far: the quality imperative in library and information services was held in Birmingham in November, organized jointly by LIRG and CERLIM (The Centre for Research and Library and Information Management of the University of Central Lancashire). The conference was well attended and some excellent papers were presented by speakers from a variety of backgrounds. I should like to thank Christine Abbott, Kay Flatten and Philip Payne, and our colleagues from CERLIM whose hard work resulted in such a successful conference.

\section{Research prizes and awards}

The 1993 TC Farries/LIRG student prizes were awarded to Krista Roberts of Thames Valley University (undergraduate) and Michael Hughes of the University of Central England (postgraduate). Runners-up were Dawn Green and Belinda Torlot respectively, both of Loughborough University. A report by Krista was published in LIRN 61, Winter 1994, and a report by Belinda will be published in a future issue of LIRN. Sadly, Michael died in September 1994. With the agreement of T C Farries and Co Ltd, and of Michael's family, his prize money has been given to the University of Central England to buy books on library and information science for the course which he studied, in his memory. The books will have a special bookplate 
and will be housed in the UCE Library. The prize award meeting was postponed until 1 March this year, when it was held at Thames Valley University, whom we thank for their hospitality. Thanks are due also to T C Farries and Co Ltd for sponsoring the prizes this year. Farries have decided to reduce their sponsorship activities and will no longer sponsor these prizes. However LIRG intends to continue funding them this year while considering future arrangements. The 1994 postgraduate prize is currently being judged. The 1994 undergraduate prizewinner is ElizabethAnn Mackie of the Robert Gordon University. Sadly, a lack of suitable applications meant that no Elsevier/LIRG Award was made this year. Elsevier have agreed that the closing date for this Award should be moved from 31 August to 15 October from 1995, and we hope that this will prove more attractive to applicants. A paper by Elisabeth Davenport, 1993 Elsevier/LIRG Award winner, was published in LIRN 61, Winter 1994. The Daphne Clarke Award was not advertised this year, and the Committee are looking at ways of relaunching this award next year.

\section{LIRN}

Ros Cotton is to be congratulated in producing three excellent issues of LIRN almost single handed again this year. In earlier years LIRN has had an Editor and a Production Editor, but for the past two years Ros has combined both roles. This is too much to ask of one person, and the Committee is urgently seeking ways of providing some assistance for Ros. Eric Davies has taken over from Monica Blake as Reviews Editor and continued to obtain interesting and up-to-date reviews for LIRN. Could I take this opportunity to remind LIRG members that Ros is always interested to receive news and reports of research for LIRN, and Eric to receive research related publications for review.

\section{Local activities}

I am disappointed to have to report that apart from the student prize award meeting at Ealing earlier this month, there have been no LIRG regional meetings. I hope this can be remedied next year, but this does require LIRG members being willing to arrange a meeting for their region.

\section{Other issues}

The report on the two meetings on the Follett report held in March 1994 was published in LIRN 60, Summer 1994, and copies were sent to the Higher Education Funding Councils and to the British Library Research and Development Department. A response was sent to the Department of National Heritage Consultatative Document on the proposal to establish a Libraries Commission. The LIRG response concentrated on issues of relevance to research in LIS. A copy was published in LIRN 60, Summer 1994. Contact has been maintained with BLRDD. A letter was sent to the Director asking if BLRDD could press for library and information community representation in the Science and Technology Assembly being set up by the European Commission. The Director replied that a UK member of the Assembly was in contact with BLRDD and would be taking an interest in information issues. The Chairman and a number of committee members attended the BLRDD Open Day in November. The Chairman also attended several of the BLRDD Information Policy Briefings during the year, and the reception held December for delegates to the European Information Research Policy Seminar, organized by BLRDD. In common with other professional groups, LIRG received an invitation from the HEFCE to comment on the assessment areas for the 1996 Research Assessment Exercise, and to nominate panel members from our field. LIRG has nominated two individuals, one of whom has also been nominated by another professional group. The outcome of the nominations is not as yet known. The Group has also responded to an invitation to comment on the British Library's Draft Automation Strategy. 
The Group has maintained contact with the IIS, the LA and BAILER. The IIS observer on the Committee, Anthony Booth, resigned during the year and discussions are being held with the IIS to appoint a replacement.

\section{And finally}

I am resigning as Chairman after three very busy and enjoyable years in which I have made many new friends. I would like to thank the Committee and the LIRG membership for their support. LIRG, although small, is a lively group, with plenty of ideas, a good publication, and financially sound. I wish my successor as Chairman, the Committee and the whole Group all the best for the future.

\section{SACHA SHAW}

Chairman 


\section{Treasurer's Report for 1994}

\section{Summary}

After a relatively quiet year in 1993, 1994 was an exceptionally busy one for the Group, with a full programme of activities during the year. This level of activity is reflected in the increased turnover. While the accounts show that we made a loss in 1994, a large part of this loss can be explained by the timing of income and expenditure across the end of the financial year, as is detailed in the notes below.

The group continues to hold substantial reserves, which have allowed us to press ahead with activities we feel are worthwhile and relevant to LIRG, despite projected losses. For example, in September 1994 the Committee agreed that the Better by far conference should go ahead, even if it ran at a loss. In the event, the conference made a very modest profit, and brought significantly increased exposure to LIRG.

\section{Notes}

1. Income from personal subscriptions is considerably less than in 1993. However, income in 1993 was unusually high, as it included income from subscriptions which had remained unpaid from the previous year (see Treasurer's report 1993). The number of personal members as at 31 December 1994 was 98 (including 2 overseas members) compared with 101 at the same time last year. Twenty-two new members joined during this year, of whom 10 took up membership as part of course/conference attendance.

2. There were 118 institutional subscriptions to LIRN at the end of the year; total UK subscriptions remained the same as the previous year at 76; overseas subscribers increased by 3 . There is some indication that the number of cancellations from public library authorities will increase in 1995. Subscription payments have been slightly slower to arrive this year, which is reflected in the reduced income at 31 December. Personal and institutional subscription rates remain unchanged for 1995 , at $£ 15$ for individuals and $£ 35$ for institutions ( $£ 40$ overseas).

3. A fuller account of the income and expenditure relating to meetings is shown on the attached sheet. All three events of the year made a net profit. As concerns the Better by far conference, additional income from delegates of $£ 3,230$ has been banked in 1995 , and a further $£ 330$ is outstanding. Since the conference was organized jointly by LIRG and the Centre for Research in Library and Information Management at University of Central Lancashire (CERLIM), it was agreed that any profit or loss would be shared. However given the small sums involved CERLIM waived its right to half share of the profits. So the projected profit to LIRG is $£ 307.82$.

4. The increase in committee expenses in 1994 is almost exclusively due to the increase in travel costs.

5. During 1994 the committee's logo and letterhead were changed, and the LIRG publicity leaflet was updated. The cost of advance publicity for events has been included under "publicity", but leaflets designed for one specific event have been included under the meetings heading. 
6. LIRN charges for 1994 include the production and despatch costs of LIRN 58 to 60 , Winter 93, Spring and Summer 94. Charges for LIRN 61 (Winter 94) will be incurred in 1995.

7. From March 1995 service improvements by the bank meant that we no longer incurred transaction charges. The charge of $£ 25.20$ relates to the first quarter of that year.

8. The expenditure of $£ 381.76$ for the Daphne Clarke award represents a payment to the 1993 award winner, Andrew Green. This money will be reclaimed from the Daphne Clarke account in 1995. LIRG has not made any grant to the Daphne Clarke fund for 1994, and no award has been made for the year.

9. The expenditure on the Elsevier award represents the award to Elizabeth Davenport for 1993. No grant will be claimed from Elsevier for 1994.

10. An error by the bank in December 1994 means that the balance shown on the bank statement at 31 December is $£ 175$ less than the cash book entry. This was corrected by the bank in January 1995.

\section{CHRISTINE ABBOTT}

LIRG Treasurer 


\section{Accounts for year ended 31 December 1994}

INCOME

Personal subscriptions

LIRN subscriptions

Meetings

LA grant

Royalties

Daphne Clark award

Elsevier award

Interest - Capital Reserve

Miscellaneous

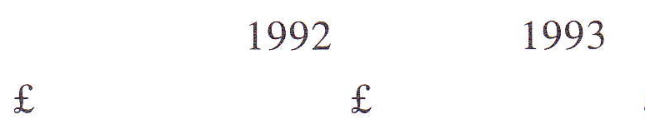

$\begin{array}{rr}854.50 & 1577.00 \\ 2930.15 & 4093.16 \\ 3043.00 & 239.00 \\ 90.00 & 90.00 \\ 46.76 & 96.15 \\ 100.00 & 50.00 \\ 1000.00 & 1000.00 \\ 89.97 & 170.16 \\ 0.00 & 6.00\end{array}$

573.81

3951.50

8912.00

0.00

187.93

0.00

0.00

280.87

0.00

8154.38

7321.47

13906.11

\section{EXPENDITURE}

Committee expenses

Publicity

Meetings

LIRN

Account charges

Administration

Daphne Clark award

Elsevier award

Student award

Unpaid cheques

Miscellaneous

\begin{tabular}{rrr}
728.00 & 681.06 & $\mathbf{9 5 1 . 3 8}$ \\
0.00 & 84.61 & $\mathbf{2 3 9 4 . 8 5}$ \\
3478.76 & 691.48 & $\mathbf{1 1 5 1 0 . 8 1}$ \\
881.82 & 826.37 & $\mathbf{2 0 5 1 . 2 1}$ \\
53.13 & 79.68 & $\mathbf{2 5 . 2 0}$ \\
147.55 & 323.68 & $\mathbf{3 7 6 . 5 3}$ \\
250.00 & 250.00 & $\mathbf{3 8 1 . 7 6}$ \\
1000.00 & 0.00 & $\mathbf{1 0 0 0 . 0 0}$ \\
& 500.00 & $\mathbf{0 . 0 0}$ \\
& 0.00 & $\mathbf{0 . 0 0}$ \\
200.00 & 0.00 & \\
\hline 6739.26 & 3436.88 & $\mathbf{1 8 6 9 1 . 7 4}$ \\
\hline 1415.12 & 3884.59 & $\mathbf{- 4 7 8 5 . 6 3}$ \\
& & \\
& & \\
& & \\
& & $\mathbf{4 7 8 5 . 6 3}$
\end{tabular}

Balance at 31 Dec 94

9255.06

\section{RECONCILIATION WITH BANK ACCOUNT}

Current Account

Capital Reserve Account
Bank statement

Add adjustment 10 Jan 95

Total

200.18

175.00

375.18

8879.88

We the undersigned certify that we have audited these accounts and that they are a true and accurate record based on the information supplied to us.

Signed:

Name

Date: 


\section{MEETINGS ACCOUNT 1994}

INCOME

AGM

27.00

Follett Fallout mtgs, London \& Leeds

1900.00

Question of Research seminar

770.00

Better by Far conference

6215.00

8912.00

EXPENDITURE

AGM

373.90

LIRG South East

0.00

Follett Fallout mtgs, London \& Leeds

1181.7

Question of Research seminar

488.03

Better by Far conference

9467.18

11510.81

\section{NET PROFIT/LOSS (to LIRG)}

f

Follett Fallout mtgs, London \& Leeds

718.30

Question of Research seminar

281.97

Better by Far conference (projected)*

307.82

1308.09

*See Treasurer's report, note 3

\section{DAPHNE CLARK AWARD}

Position as at 31 December 1994

$\mathfrak{f}$

Balance at 1 January 1994

821.36

Interest for the year

5.75

Balance as at 31 December 1994 


\title{
TC Farries/LIRG Student Prizes 1993
}

The 1993 TC Farries/LIRG Student Prizes were presented by David Dean of TC Farries \& Co Ltd at a LIRG meeting held at Thames Valley University on 1 March 1995. Undergraduate winner was Krista Roberts of Thames Valley University for her dissertation A quality assurance programme for St Francis Xavier College Library. Krista spoke about her research at the meeting, and has published a report in Library and Information Research News 61, Winter 1994. The Postgraduate Prize was awarded to Michael Hughes of the University of Central England for his MSc dissertation A consideration of natural language processing in relation to the relevance evaluation of text records retrieved by database searching. Sadly, Michael died in September 1994 before he could be presented with his prize and write up a summary of his research for LIRN. With the agreement of Michael's family, and the TC Farries and Co Ltd, his prize money has been given to the Library of the University of Central England to buy books in his memory, to be used by students taking the MSc course which he took. A special bookplate is being designed.

Runners-up were Dawn Green (undergraduate) and Belinda Torlot (postgraduate), both of Loughborough University. Belinda attended the meeting on 1 March 1995 to speak and to demonstrate her work Willkommen in München: a hypercard database for use in teaching German. A summary of this project in this issue ofLibrary and Information Research News. The judges were impressed by the high standard of the work entered for the prizes.

The undergraduate winner and runner-up both produced pieces of work of direct and timely professional relevance. The undergraduate judging panel commented that Krista Roberts' work provided an outstanding contribution to the literature of the field and that the findings of Dawn Green's project, The use of hypermedia in a guide to the Pilkington Library would clearly be useful to others considering this approach to user education. As general points, the panel felt that there was scope for candidates to comment/evaluate the applicability of the chosen methodology at some point within their work, and that it was important for candidates to go outside the library and information literature in order to place their research within a wider socioeconomic context.

The judges for the postgraduate prize commented that the winner, Michael Hughes, showed excellent understanding of his subject, and organized and discussed his material methodically and with clarity. Runner-up Belinda Torlot produced an original piece of creative work which was a tool for teaching both information and language skills. It was interesting to note that there were no surveys among these postgraduate prize entries (surveys having predominated in the previous year). Two of the entries, the winner included, were theoretical studies, which are difficult to carry off at MSc level where there is a danger of being over ambitious. The quality of the bibliographies was better than the year before, but there were still some careless errors and omissions. Objectives were not always clearly stated and in some dissertations the abstract appeared to serve as introduction and statement of objectives.

Unfortunately, following some changes within TC Farries and Co Ltd, the company have decided not to continue sponsorship of these prizes. However, LIRG intends to continue the prizes and is actively seeking alternative sponsorship. In the meantime LIRG will fund the prizes for 1994.

\author{
SACHA SHAW \\ Former Chair, LIRG
}

